Egyptian

Orthodontic Journal

\title{
EVALUATION OF THE SKELETAL, DENTAL AND SOFT TISSUE EFFECTS OF CLASS III SPLINTS (CLINICAL STUDY)
}

\author{
Engy A. El-Masry ${ }^{1}$, Essam M. Abdallah ${ }^{2}$, Mohamed I. Mowafy ${ }^{3}$ \\ ABSTRACT:
}

Objective: The aim of this study was to evaluate the skeletal, dental and soft tissue effects of using Class III splints in the treatment of skeletal Class III malocclusion in growing patients. Materials and Methods: The appliance was tested on ten growing skeletal Class III patients with an anterior crossbite. Digital Cateral cephalometric radiographs were taken before treatment and after crossbite correction. The pre and post radiographs were traced and skeletal, dental and soft tissue measurements were calculated with the use of the computer software FACAD. Evaluation of the effects was by statistical comparison of the pre and post treatment measurements. Results: There was a marked clinical improvement in the form of correction of the anterior crossbite and improvement of the patient's profile, which raised the self esteem of the patients. The statistical analysis showed skeletal effects in the form of an increase in the $\mathcal{A N} \mathfrak{N}$ difference, Wits appraisal, mandibular plane to Frankfort horizontal plane angle and convexity angle, and a significant decrease in the occlusal plane to Frankfort horizontal plane angle. Dental effects were in the form of an upper incisor proclination, lower incisor retroclination, upper molar proclination and lower molar

1- Post graduate student, Orthodontics department, Faculty of Dentistry, Alexandria University

2- Professor and Head of Orthodonics department,Faculty of Dentistry, Alexandria University.

3- Assistant Professor of Orthodontics, Faculty of Dentistry, Alexandria University. 
Egyptian

Orthodontic Journal

retroclination, an increase in the overjet and molar relation, and a decrease in the overbite. Soft tissue effects were in the form of a backward movement of the soft tissue chin and the lower lip, and a forward movement of the upper lip. Conclusion: Class III splints can be used in the treatment of growing skeletal Class III malocclusion that is due to a combination of maxillary retrusion and mandibular protrusion. It is more indicated though with deep bite cases, unless it will be followed with phase II extraction or with the use of high pull head gear.

\section{INTRODUCTION}

Class III malocclusion is one of the most challenging clinical situations in the orthodontic field. So, it became the subject of interest in many investigations. ${ }^{1,2}$ Treatment of skeletal Class III malocclusion has been extensively researched and widely divergent views on treatment philosophies have been proposed. Because of the nature of the malocclusion and the ensuing dentofacial deformity, many parents seek treatment for their children at an early age. However, there is an ongoing dilemma between early treatment of the developing Class III malocclusion in the growing patient and late treatment in the adult stage. ${ }^{3}$ In the adult patients, the only options available for treatment are by camouflaging the Class III malocclusion with fixed appliances or by performing orthognathic surgery if the skeletal discrepancy is severe. However, different treatment modalities are available to the clinician for the early interceptive treatment of developing Class III malocclusion. These include orthopedic appliances (as facemask ${ }^{4-7}$, Tandem Traction Bow Appliance (TTBA) ${ }^{8}$, Modified Tandem Appliance (MTA $)^{9,10}$ or chin cup $^{11,12}$ ), functional appliances (as Frankel-III appliance ${ }^{13}$, Class III or reverse twin block ${ }^{14}$, magnetic appliance $e^{15}$ or removable mandibular retractor ${ }^{16}$ ), double-plate appliance $(\mathrm{DPA})^{17}$, bone anchored maxillary protraction ${ }^{18-21}$ or Class III splints. Each appliance has it's mode of action that should be considered in its choice according to the criteria of the patient to be treated.

Class III splints is a bimaxillary intraoral removable appliance consisting of two acrylic splints with flat occlusal planes for the upper and lower arches

Volume 43 - June 2013 
Egyptian

Orthodontic Journal

with hooks for the attachment of intraoral Class III elastics.Class III splints were evaluated for the treatment of developing class III malocclusion by different authors and different results were obtained. Franchi and Baccetti ${ }^{22}$ used it for the correction of skeletal Class III malocclusion in the primary dentition for only two cases and skeletal and dental effects were obtained. El Kenany and Ismail ${ }^{23}$ compared the Class III splint to the facemask for early treatment of Class III malocclusion. They found more dental than skeletal effects of the splints in comparison to more skeletal effects of the facemask. El-Harouni ${ }^{24}$ conducted another study to evaluate the skeletal, dental and soft tissue effects of the Class III splints for the treatment of growing Class III patients. It concluded that Class III splints caused skeletal as well as dental and soft tissue effects. So, due to this controversy between the results of different studies and due to the scarce literature review available on the appliance, the purpose of this clinical study was to further evaluate the skeletal, dental and soft tissue effects of the Class III splints. A computer software was used for this evaluation, as it can easily help in measuring more angular and linear measurements than those used in the previous studies.

\section{MATERIALS AND METHODS}

1. Ten patients were selected from the clinic of the Orthodontic Department, Faculty of Dentistry, Alexandria University according to the following criteria:-

- Growing patients with an age range of 8-10 years in female patients and $8-12$ years in male patients. ${ }^{25}$

- Skeletal Class III malocclusion identified by an anterior crossbite ranging from 2-4 mm, an ANB difference of less than 0.5 degrees and Wits appraisal of less than $-5 \mathrm{~mm}$.

- No previous orthodontic or orthopedic treatment.

The exclusion criteria were:

- Severe craniofacial anomalies e.g. clefts.

- Functional shifts i.e. pseudo Class III.

2. Upper and lower alginate impressions were taken for each patient and poured in stone twice as working and pre-treatment study models. 
3. In addition to the upper and lower study models other pre-treatment diagnostic records were taken including:

- Extra oral and intraoral photographs.

- Digital panoramic and lateral cephalometric radiographs.

4. Class III splints (Fig.1) were fabricated from two acrylic splints with smooth occlusal surfaces totally covering the maxillary and mandibular arches and extending up to a few millimeters short of the buccal and lingual sulci. Adam's clasps were used on the permanent first molars for retention . Hooks were placed distal to the upper second primary molar or 2nd premolar and mesial to the lower primary canine for Class III elastic placement.

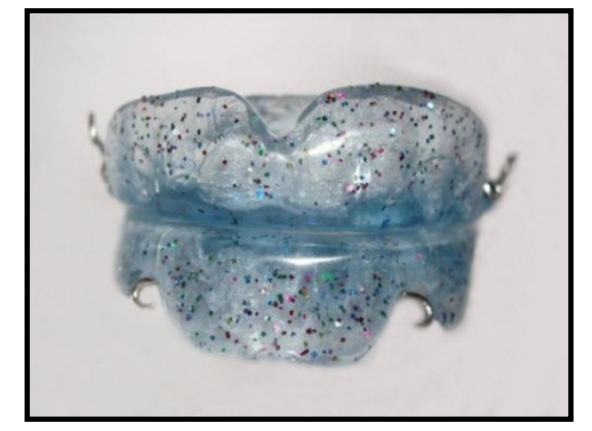

Fig. 1: Class III splints appliance.

5. The Class III splints were inserted into the patient's mouth and checked for parallel occlusal surfaces, fit and retention and any pressure areas were released from the acrylic base.

6. The size of the intraoral Class III elastics was chosen as to apply a force of $350 \mathrm{gm}$ per side. ${ }^{26}$ The force was calibrated by using a force gauge* .

7. The patients and their parents were given the following instructions:

i. The appliance should be worn full time except at mealtimes and at the time of teeth brushing.

ii. The elastics should be changed every 24 hours

* Correx tension gauge. Haag-Streit, Bern, Switzerland. 
iii. Elastics with a force of $250 \mathrm{gm}$ should be worn first (Fig. 2) and after one week of insertion of the first elastics the second elastics with a force of $100 \mathrm{gm}$ should be added to reach the required total force of 350 gm per side. ${ }^{26}$

iv. The appliance should be washed and cleaned thoroughly daily.
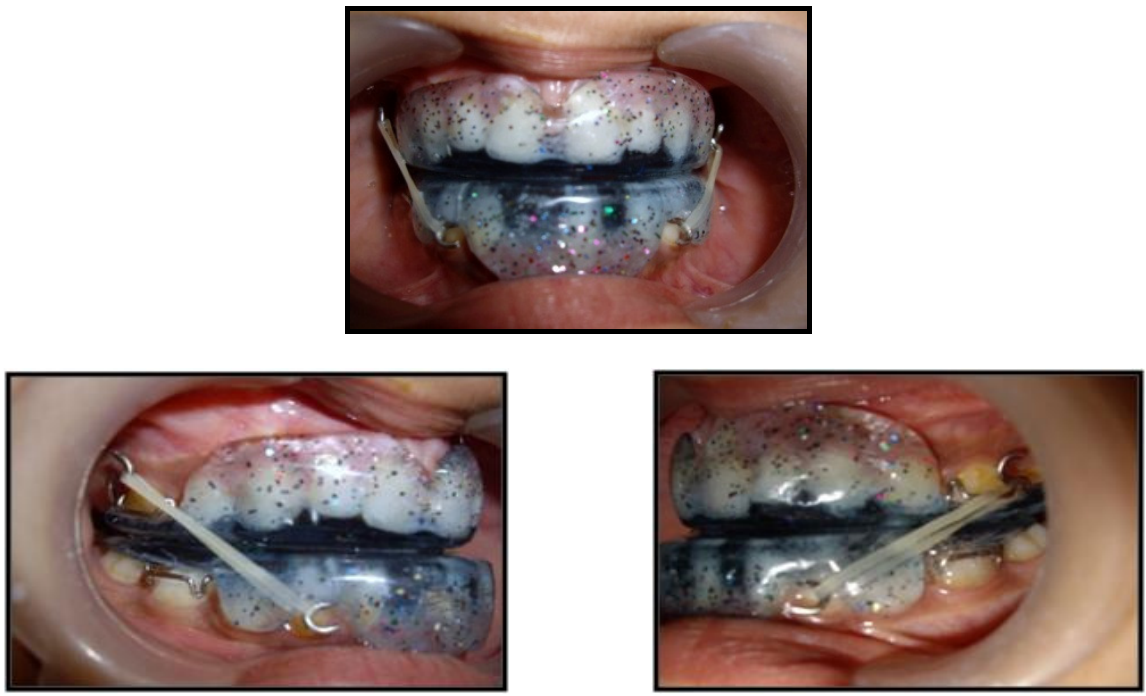

Fig. 2: Intraoral views of the Class III splints with Class III elastics.

8. The patients were seen one week later to verify compliance, check the retention of the appliance and gingiva for any ulcers.

9. The patients were scheduled on a monthly basis to monitor the progress till the complete correction of the anterior crossbite and achievement of $2 \mathrm{~mm}$ of over jet.

10. Post treatment diagnostic records were taken including

- Study casts

- Extraoral and intraoral photographs

- Digital panoramic and lateral cephalometric radiographs.

11. A customized analysis was prepared on a computer software FACAD ${ }^{* *}$, which included 24 skeletal measurements, 11 dental measurements and 15 soft tissue measurements.

\footnotetext{
(Ilexis AB, Linköping, Sweden).
} 
12. The pre and post treatment lateral cephalometric radiographs were imported into the software and calibrated using the x-ray system ruler.

13. The landmarks were plotted on the x-rays manually using the mouse. To ensure their accurate placement, contrast/brightness and zooming of the $\mathrm{x}$-rays was applied as well as rotations were done when necessary to ensure a horizontal position of the Frankfort horizontal plane.

14. A duplicate of each $\mathrm{x}$-ray was done to trace it twice.

15. The measurements were then automatically calculated by the software.

16. The pre and post measurements were subjected to the statistical analysis.

17. All patients were instructed to continue wearing the appliance after the results were taken for three to four months for stability and they were followed up also on a monthly basis. Then they were instructed to wear the appliance only at night with a force of $100 \mathrm{gm}$, as a retentive period till the patient ceases growth or when the second phase of treatment if required starts. ${ }^{22}$

\section{Reliability of landmark identification and measurements}

All landmarks were identified on each x-ray twice on separate occasions, and both were checked for accuracy of location by a second investigator. Two measurements for each x-ray were thereby calculated by the software and the mean of the two measurements was taken, provided that the difference between the two measurements didn't exceed $0.5 \mathrm{~mm}$ or $0.5^{\circ}$ (random error), otherwise a third measurement was taken and the mean of the nearest two was used.

\section{Statistical analysis of the data}

Data was fed to the computer using SPSS software package version 19.0.Quantitative data were described using mean and standard deviation. Paired t-test was used to determine the significance of the changes after treatment. Significance of the obtained results was judged at the 5\% level. 
Egyptian

Orthodontic Journal

\section{Landmarks plotted on the lateral cephalometric radiographs}

Table I: Skeletal landmarks. (Fig. 3)

\begin{tabular}{|l|l|}
\hline $\mathbf{N}$ & Nasion \\
\hline S & Sella turcica \\
\hline Or & Orbitale \\
\hline P & Porion \\
\hline ANS & Anterior Nasal Spine \\
\hline PNS & Posterior Nasal Spine \\
\hline A & Downs' A-point \\
\hline B & Downs' B-point \\
\hline Ar & Articulare \\
\hline Go & Gonion \\
\hline Me & Menton \\
\hline Pog & Pogonion \\
\hline OLp & Occlusal Line, posterior point * \\
\hline
\end{tabular}

* The posterior point of the occlusal line is one of the landmarks plotted manually, whereas the anterior point of the occlusal line is a constructed marker (OLa) plotted automatically by the software at midpoint between the dental markers $<$ Is $>$ and $<$ Ii $>$ (Fig.5).

Table II: Dental landmarks. (Fig.4)

\begin{tabular}{|l|l||}
\hline Is & Incisor superior (upper central incisor tip) \\
\hline Isa & Incisor superior apex (upper central incisor root apex) \\
\hline Isl & $\begin{array}{l}\text { Incisor superior labial outline (most mesial point of the lower central incisor's } \\
\text { labial outline) }\end{array}$ \\
\hline Ii & Incisor inferior (lower central incisor tip) \\
\hline Iia & Incisor inferior apex (lower central incisor root apex) \\
\hline Iil & $\begin{array}{l}\text { Incisor inferior labial outline (most mesial point of the upper central incisor's } \\
\text { labial outline) }\end{array}$ \\
\hline Ms-c & Molar superior-cusp (cusp tip of the upper $1^{\text {st }}$ molar) \\
\hline Ms-m & Molar superior- mesial (most mesial point of the upper $1^{\text {st }}$ molar crown) \\
\hline Ms-b & Molar superior-bifurcation (bifurcation of lower $1^{\text {st }}$ molar roots) \\
\hline Mi-c & Molar inferior-cusp (cusp tip of the lower $1^{\text {st }}$ molar) \\
\hline Mi-m & Molar inferior-mesial (most mesial point of the lower $1^{\text {st } \text { molar crown) }}$ \\
\hline Mi-b & Molar inferior-bifurcation (bifurcation of lower $1^{\text {st }}$ molar roots) \\
\hline
\end{tabular}

Volume 43 - June 2013 
Egyptian

Orthodontic Journal

Table III: Soft tissue landmarks. (Fig.3)

\begin{tabular}{||l|l|}
\hline GL & Soft tissue Glabella \\
\hline Ns & Soft tissue Nasion \\
\hline PRN & Pronasale (tip of the nose) \\
\hline MS & Steiner's S-point (columnella tangent point) \\
\hline SN & Subnasale; Retronasale \\
\hline SLs & Sulcus Labial superior; soft tissue A point \\
\hline Ls & Labrale superior (the most anterior part on the convexity of the upper lip) \\
\hline Li & Labrale inferior (the most anterior part on the convexity of the upper lip) \\
\hline SLi & Sulcus Labial inferior; soft tissue B point \\
\hline PGs & Soft tissue Pogonion \\
\hline GNs & Soft tissue Gnathion \\
\hline
\end{tabular}

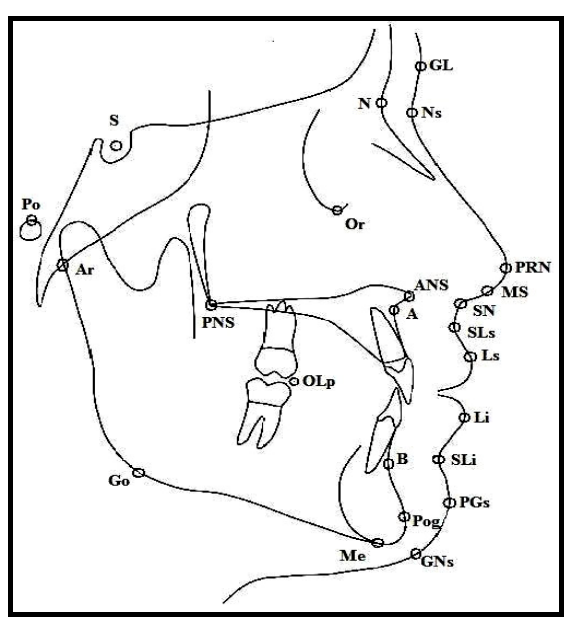

Fig. 3: Skeletal and soft tissue landmarks plotted on the lateral cephalometric radiographs.

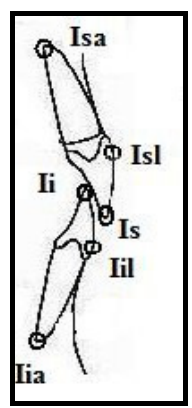

Fig. 4: Dental landmarks plotted on the lateral cephalometric radiographs.

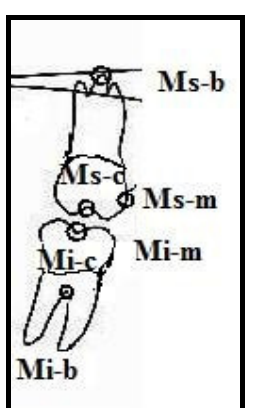

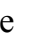

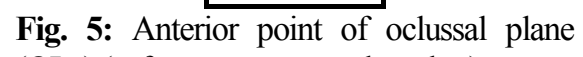
(OLa) (software constructed marker). 


\section{Planes and Lines constructed by the software on the Lateral cephalometric radiographs to be used in the measurements}

Table IV: Skeletal and soft tissue planes and lines. (Fig.6)

\begin{tabular}{||l|l|}
\hline SN plane & Plane defined by the landmarks $<\mathrm{S}>$ and $<\mathrm{N}>$ \\
\hline Frankfort Horizontal plane (FH) & Plane defined by the landmarks $<$ Po $>$ and $<$ Or $>$ \\
\hline Palatal plane / Nasal line (NL) & Plane defined by the landmarks $<$ ANS $>$ and $<$ PNS $>$ \\
\hline Functional occlusal plane (OL) & Plane defined by the landmarks $<$ OLp $>$ and $<$ OLa $>$ \\
\hline Mandibular plane (ML) & Plane defined by the landmarks $<$ Go $>$ and $<$ Me $>$ \\
\hline Facial line & Line defined by the landmarks $<\mathrm{N}>$ and $<$ Pog $>$ \\
\hline Soft tissue facial line & Line defined by the landmarks $<\mathrm{Ns}>$ and $<$ PGs $>$ \\
\hline E line (EL) & Line defined by the landmarks $<$ PRN $>$ and $<$ PGs $>$ \\
\hline
\end{tabular}

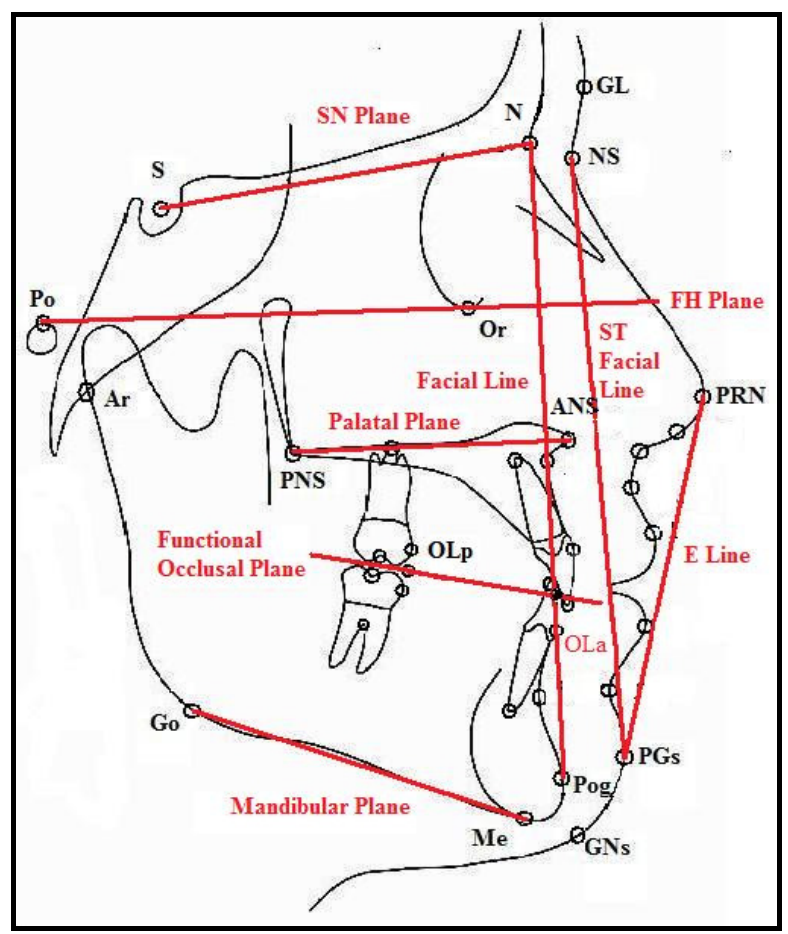

Fig. 6: Skeletal and soft tissue planes and lines. 
Egyptian

Orthodontic Journal

Table V: Dental lines. (Fig. 7)

\begin{tabular}{|l|l|}
\hline Upper incisor long axis (IsL) & Line defined by the landmarks $<\mathrm{Is}>$ and $<$ Isa $>$. \\
\hline Lower incisor long axis (IiL) & Line defined by the landmarks $<\mathrm{Ii}>$ and $<\mathrm{Iia}>$. \\
\hline Upper molar long axis (MsL) & Line defined by the landmarks $<$ Ms-c $>$ and $<$ Ms-b $>$. \\
\hline Lower molar long axis (MiL) & Line defined by the landmarks $<$ Mi-c $>$ and $<$ Mi-b $>$. \\
\hline
\end{tabular}

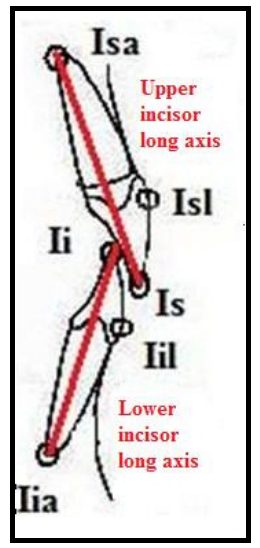

Upper and lower incisors long axis.

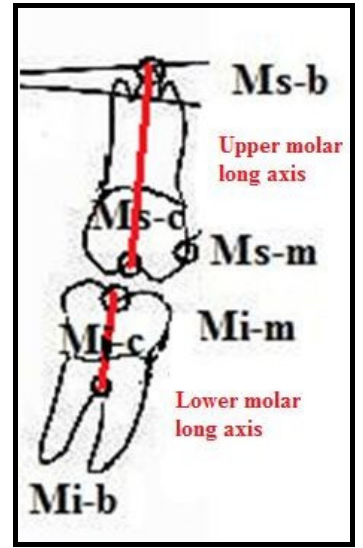

Upper and lower molars long axis.

Fig. 7: Dental lines.

\section{Measurements}

\section{I - Skeletal Measurements}

Angular measurements (degree): SNA, SNB, ANB, SNPog, Facial angle, Convexity angle, FH/NL (Palatal plane to Frankfort horizontal plane angle), ML/FH (Mandibular plane to Frankfort horizontal plane angle), Gonial angle (The angle around the center $<\mathrm{Go}>$ and between the markers $<\mathrm{Ar}>$ and $<\mathrm{Me}>$ ), OL/FH (Functional occlusal plane to Frankfort horizontal plane angle). 
Egyptian

Orthodontic Journal

Linear measurements (mm): A-NP (distance between the markers $<\mathrm{N}>$ and $<\mathrm{A}>$ from their perpendicular projection on the FH plane), B-NP (distance between the markers $<\mathrm{N}>$ and $<\mathrm{B}>$ from their perpendicular projection on the FH plane, Wits appraisal, Pog-NP (distance between the markers $<\mathrm{N}>$ and $<\mathrm{Pog}>$ from their perpendicular projection on the FH plane), PNS-ANS (distance between the markers $<$ PNS $>$ and $<$ ANS $>$ from their perpendicular projection on the FH plane), S-PNS(distance between the markers $<\mathrm{S}>$ and $<\mathrm{PNS}>$ from their perpendicular projection on the FH plane), Ramus height (The distance between the markers $<\mathrm{Ar}>$ and $<$ Go $>$ ), Body length (The distance between the markers $<$ Go $>$ and $<\mathrm{Me}>$ ), UFH (distance between the markers $<\mathrm{ANS}>$ and $<\mathrm{N}>$ from their perpendicular projection on the SN plane), LFH (distance between the markers $<\mathrm{Me}>$ and $<\mathrm{ANS}>$ from their perpendicular projection on the $\mathrm{SN}$ plane), U:L facial height $(<\mathrm{UFH}>$ divided by $<\mathrm{LFH}>$ ), PFH (distance between the markers $<\mathrm{S}>$ and $<\mathrm{Go}>$ ), AFH (distance between the markers $<\mathrm{N}>$ and $<\mathrm{Me}>$ ), P:A facial height $(<\mathrm{PFH}>$ divided by $<\mathrm{AFH}>$ ).

\section{II - Dental Measurements}

Angular measurements (degree): IsL/FH (angle between the upper incisor long axis and the FH plane), IiL/MP (angle between the lower incisor long axis and the mandibular plane), MsL/FH (angle between the FH plane and the upper molar long axis), MiL/MP (angle between the lower molar long axis and the mandibular plane).

Linear measurements $(\mathbf{m m})$ : Is-NP (distance between the markers $<\mathrm{N}>$ and $<$ Is $>$ from their perpendicular projection on the FH plane), Ii-NP (distance between the markers $<\mathrm{N}>$ and $<\mathrm{Ii}>$ from their perpendicular projection on the FH plane), Overjet ( horizontal distance between the markers $<\mathrm{Ii}>$ and $<\mathrm{Is}>$ from their perpendicular projection on the $\mathrm{FH}$ plane), Overbite (vertical distance between the markers $<$ Is $>$ and $<\mathrm{Ii}>$ from their perpendicular projection on the FH plane), Ms-m-NP (distance between the markers $<\mathrm{N}>$ and $<\mathrm{Ms}-\mathrm{m}>$ from their perpendicular projection on the FH plane), Mi-m-NP (distance between the markers $<\mathrm{N}>$ and $<\mathrm{Mi}-\mathrm{m}>$ from their perpendicular projection on the $\mathrm{FH}$ plane), Molar relation (distance between the markers $<$ Mi-m $>$ and $<$ Ms-m $>$ from their perpendicular projection on the $\mathrm{FH}$ plane). 
Egyptian

Orthodontic Journal

\section{III - Soft tissue Measurements}

Angular measurements (degree): Nasolabial angle, Facial ST angle (angle between the soft tissue facial line and the FH plane).

Linear measurements $(\mathbf{m m})$ : Ls-EL (distance between the E line and the marker $<\mathrm{Ls}>$ ), Li-EL (distance between the $\mathrm{E}$ line and the marker $<\mathrm{Li}>$ ), Ls curvature (distance between the markers $<\mathrm{SLs}>$ and $<\mathrm{Ls}>$ from their perpendicular projection on the $\mathrm{FH}$ plane), Li curvature (distance between the markers $<\mathrm{SLi}>$ and $<\mathrm{PGs}>$ from their perpendicular projection on the FH plane), A-SN (distance between the markers $<\mathrm{A}>$ and $<\mathrm{SN}>$ from their perpendicular projection on the $\mathrm{FH}$ plane), Ls strain (distance between the markers $<$ Isl $>$ and $<$ Ls $>$ from their perpendicular projection on the $\mathrm{FH}$ plane), Ls strain factor $(<\mathrm{A}-\mathrm{SN}>$ subtracted by $<$ Ls strain $>$ ), B-SLi (distance between the markers $\angle \mathrm{B}>$ and $<\mathrm{SLi}>$ from their perpendicular projection on the $\mathrm{FH}$ plane), Li strain (distance between the markers $<$ Iil $>$ and $<\mathrm{Li}>$ from their perpendicular projection on the $\mathrm{FH}$ plane), Li strain factor $(<\mathrm{B}-\mathrm{SLi}>$ subtracted by $<$ Li strain $>$ ), Ns-PGs/FH (distance between the markers $<$ Ns $>$ and $<$ PGs $>$ from their perpendicular projection on the $\mathrm{FH}$ plane), U:L ST facial height (distance between the markers $<\mathrm{GL}>$ and $<\mathrm{SN}>$ divided by the distance between the markers $<\mathrm{SN}>$ and $<\mathrm{GNs}>$ ), Chin thickness (distance between the markers $<$ Pog $>$ and $<$ PGs $>$ ).
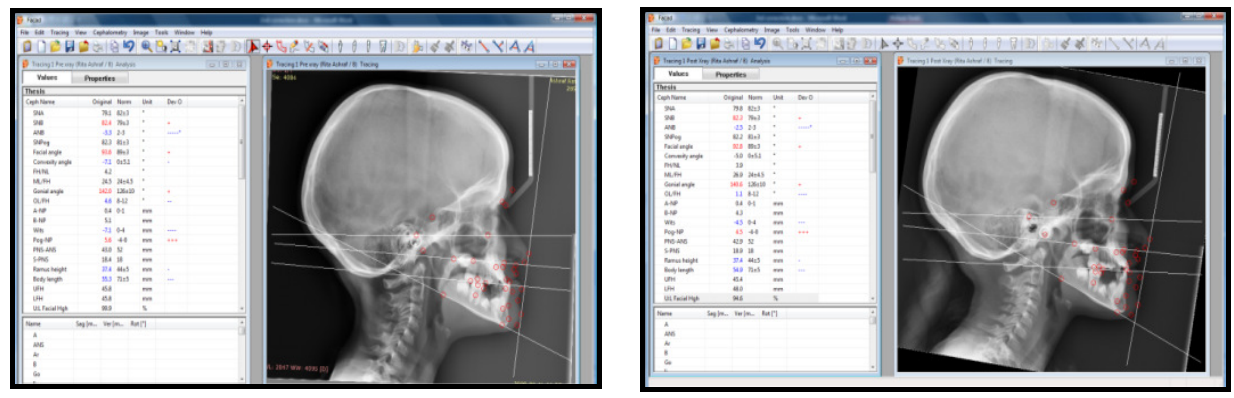

Fig. 8: Software screen image showing the tracing and analysis of the pre and post lateral cephalometric x-rays of one of the patients.

Volume 43 - June 2013 


\section{RESULTS}

The anterior crossbite was corrected within three to six months. All patients showed marked clinical improvement in their profiles after anterior cross bite correction. Some pre and post treatment measurements showed a statistically significant change

Table VI shows descriptive statistics of the comparison between the angular skeletal measurements before and after treatment. There was a significant increase in the ANB difference, mandibular plane to Frankfort horizontal plane angle $(\mathrm{ML} / \mathrm{FH})$, and convexity angle. However, there was a significant decrease in the oclussal plane to Frankfort horizontal plane angle $(\mathrm{OL} / \mathrm{FH})$.

Table VI: Descriptive statistics and Paired t-test for pre and post angular skeletal measurements.

\begin{tabular}{|l|c|c|c|}
\hline $\begin{array}{c}\text { Angular skeletal } \\
\text { measurement (degree ) }\end{array}$ & $\begin{array}{c}\text { Pre } \\
\text { Mean } \pm \text { SD }\end{array}$ & $\begin{array}{c}\text { Post } \\
\text { Mean } \pm \text { SD }\end{array}$ & $\begin{array}{c}\text { P value of } \\
\text { Paired t- test }\end{array}$ \\
\hline SNA & $80.89 \pm 4.44$ & $81.52 \pm 2.49$ & 0.224 \\
\hline SNB & $83.06 \pm 4.41$ & $81.37 \pm 1.82$ & 0.267 \\
\hline ANB & $\mathbf{- 2 . 5 1} \pm \mathbf{2 . 0 2}$ & $\mathbf{0 . 0 9} \pm \mathbf{1 . 9 5}$ & $\mathbf{0 . 0 0 3}$ \\
\hline SNPog & $84.29 \pm 5.19$ & $83.16 \pm 4.60$ & 0.417 \\
\hline Facial angle & $92.18 \pm 2.53$ & $90.23 \pm 3.16$ & 0.061 \\
\hline Convexity angle & $\mathbf{- 4 . 6 8} \pm \mathbf{5 . 7 2}$ & $\mathbf{0 . 3 3} \pm \mathbf{4 . 8 4}$ & $\mathbf{0 . 0 0 6}$ \\
\hline FH/NL & $-0.35 \pm 4.39$ & $-0.64 \pm 5.13$ & 0.636 \\
\hline ML/FH & $\mathbf{2 4 . 7 6 \pm \mathbf { 3 . 3 1 }}$ & $\mathbf{2 6 . 4 4} \pm \mathbf{3 . 8 9}$ & $\mathbf{0 . 0 1 8}$ \\
\hline Gonial angle & $132.64 \pm 6.27$ & $131.57 \pm 5.20$ & 0.371 \\
\hline OL/FH & $\mathbf{6 . 1 9} \pm \mathbf{2 . 2 9}$ & $\mathbf{4 . 0 1} \pm \mathbf{2 . 6 9}$ & $\mathbf{0 . 0 1 4}$ \\
\hline
\end{tabular}

*: Statistically significant at $\mathrm{P} \leq 0.05$

Table VII shows descriptive statistics of the comparison between the linear skeletal measurements before and after treatment. There was a significant increase in the Wits appraisal. 
Egyptian

Orthodontic Journal

Table VII: Descriptive statistics and Paired t-test for pre and post linear skeletal measurements.

\begin{tabular}{||l|c|c|c||}
\hline $\begin{array}{c}\text { Linear skeletal } \\
\text { measurement } \mathbf{( m m )}\end{array}$ & $\begin{array}{c}\text { Pre } \\
\text { Mean } \pm \text { SD }\end{array}$ & $\begin{array}{c}\text { Post } \\
\text { Mean } \pm \text { SD }\end{array}$ & $\begin{array}{c}\text { P value of Paired } \\
\text { t- test }\end{array}$ \\
\hline A-NP & $0.04 \pm 3.01$ & $0.21 \pm 2.70$ & 0.705 \\
\hline B-NP & $2.49 \pm 5.14$ & $-0.47 \pm 4.71$ & 0.085 \\
\hline Wits & $\mathbf{- 7 . 5 4} \pm \mathbf{3 . 4 6}$ & $\mathbf{- 3 . 3 1} \pm \mathbf{2 . 9 5}$ & $\mathbf{0 . 0 0 1}$ \\
\hline Pog-NP & $2.59 \pm 3.12$ & $0.19 \pm 5.70$ & 0.135 \\
\hline PNS-ANS & $49.04 \pm 7.54$ & $46.77 \pm 3.21$ & 0.410 \\
\hline S-PNS & $18.81 \pm 1.83$ & $17.88 \pm 1.26$ & 0.169 \\
\hline Ramus height & $41.37 \pm 6.06$ & $40.66 \pm 2.78$ & 0.747 \\
\hline Body length & $67.62 \pm 13.61$ & $63.15 \pm 3.73$ & 0.387 \\
\hline UFH & $47.88 \pm 5.38$ & $47.55 \pm 5.17$ & 0.857 \\
\hline LFH & $52.76 \pm 4.28$ & $57.74 \pm 9.32$ & 0.147 \\
\hline U:L facial height & $86.29 \pm 11.84$ & $83.17 \pm 11.08$ & 0.365 \\
\hline PFH & $68.25 \pm 11.97$ & $68.37 \pm 7.13$ & 0.974 \\
\hline AFH & $110.54 \pm 20.60$ & $106.71 \pm 11.18$ & 0.198 \\
\hline P:A facial height & $64.17 \pm 3.35$ & $63.61 \pm 2.62$ & 0.444 \\
\hline
\end{tabular}

*: Statistically significant at $\mathrm{P} \leq 0.05$

Table VIII shows descriptive statistics of the comparison between the angular dental measurements before and after treatment. There was a significant increase in the IsL/FH and $\mathrm{MsL} / \mathrm{FH}$ angles and a significant decrease in the IiL/ML and MiL/ML angles.

Table VIII: Descriptive statistics and Paired t-test for pre and post angular dental measurements.

\begin{tabular}{||c|c|c|c|}
\hline $\begin{array}{c}\text { Angular dental } \\
\text { measurement (degree) }\end{array}$ & $\begin{array}{c}\text { Pre } \\
\text { Mean } \pm \text { SD }\end{array}$ & $\begin{array}{c}\text { Post } \\
\text { Mean } \pm \text { SD }\end{array}$ & $\begin{array}{c}\text { P value of } \\
\text { Paired t- test }\end{array}$ \\
\hline IsL/FH & $114.43 \pm 7.51$ & $121.0 \pm 6.32$ & $<0.001^{*}$ \\
\hline IiL/ML & $87.46 \pm 5.02$ & $83.61 \pm 2.89$ & $0.039^{*}$ \\
\hline MsL/FH & $81.18 \pm 4.04$ & $84.97 \pm 4.79$ & $<0.001^{*}$ \\
\hline MiL/ML & $77.69 \pm 4.11$ & $73.77 \pm 2.43$ & $0.013^{*}$ \\
\hline
\end{tabular}

*: Statistically significant at $\mathrm{P} \leq 0.05$

Volume 43 - June 2013 
Table IX shows descriptive statistics of the comparison between the linear dental measurements before and after treatment. There was a significant increase in the Is-NP distance, overjet and molar relation. However, there was a significant decrease in the overbite.

Table IX: Descriptive statistics and Paired t-test for pre and post linear dental measurements.

\begin{tabular}{||l|c|c|c|}
\hline $\begin{array}{c}\text { Linear dental } \\
\text { measurement }(\mathbf{m m})\end{array}$ & $\begin{array}{c}\text { Pre } \\
\text { Mean } \pm \text { SD }\end{array}$ & $\begin{array}{c}\text { Post } \\
\text { Mean } \pm \text { SD }\end{array}$ & $\begin{array}{c}\text { P value of Paired } \\
\text { t- test }\end{array}$ \\
\hline Is-NP & $3.86 \pm 5.23$ & $6.33 \pm 6.39$ & $0.002^{*}$ \\
\hline Ii-NP & $-4.32 \pm 2.0$ & $-2.65 \pm 1.70$ & $0.007^{*}$ \\
\hline Overjet & $-3.28 \pm 1.29$ & $2.49 \pm 0.49$ & $<0.001^{*}$ \\
\hline Overbite & $3.90 \pm 2.39$ & $2.01 \pm 1.64$ & $0.012^{*}$ \\
\hline Ms-m-NP & $-22.03-3.70$ & $-20.88 \pm 3.41$ & 0.214 \\
\hline Mi-m-NP & $-18.54 \pm 5.52$ & $-20.32 \pm 3.21$ & 0.165 \\
\hline Molar relation & $\mathbf{- 3 . 2 4} \pm \mathbf{2 . 3 6}$ & $\mathbf{0 . 4 7} \pm \mathbf{2 . 9 5}$ & $\mathbf{0 . 0 0 1}$ \\
\hline
\end{tabular}

*: Statistically significant at $\mathrm{P} \leq 0.05$

Table X shows descriptive statistics of the comparison between the angular soft tissue measurements before and after treatment. There was a significant decrease in the facial ST angle. However, there was a non significant change in the nasolabial angle.

Table X: Descriptive statistics and Paired t-test for pre and post angular soft tissue measurements.

\begin{tabular}{||c|c|c|c|}
\hline $\begin{array}{c}\text { Angular soft tissue } \\
\text { measurement (degree) }\end{array}$ & $\begin{array}{c}\text { Pre } \\
\text { Mean } \pm \text { SD }\end{array}$ & $\begin{array}{c}\text { Post } \\
\text { Mean } \pm \text { SD }\end{array}$ & $\begin{array}{c}\text { P value of Paired } \\
\text { t- test }\end{array}$ \\
\hline Nasolabial angle & $107.05 \pm 6.97$ & $108.64 \pm 7.22$ & 0.583 \\
\hline Facial ST angle & $\mathbf{9 7 . 2 3} \pm \mathbf{3 . 3 4}$ & $\mathbf{9 5 . 1 1} \pm \mathbf{4 . 8 4}$ & $\mathbf{0 . 0 3 3}$ \\
\hline
\end{tabular}

*: Statistically significant at $\mathrm{P} \leq 0.05$ 


\section{Egyptian \\ Orthodontic Journal}

Table XI shows descriptive statistics of the comparison between the linear soft tissue measurements before and after treatment. There was a significant increase in the Li-EL distance. However, there was a significant decrease in the Ls-EL distance and Ns-PGs/FH.

Table XI: Descriptive statistics and Paired t-test for pre and post linear soft tissue measurements.

\begin{tabular}{|l|c|c|c|}
\hline \multicolumn{1}{|c|}{$\begin{array}{c}\text { Linear soft tissue } \\
\text { measurement } \mathbf{( m m )}\end{array}$} & $\begin{array}{c}\text { Pre } \\
\text { Mean } \pm \text { SD }\end{array}$ & $\begin{array}{c}\text { Post } \\
\text { Mean } \pm \text { SD }\end{array}$ & $\begin{array}{c}\text { P value of Paired } \\
\text { t- test }\end{array}$ \\
\hline Ls-EL & $\mathbf{- 5 . 4 6} \pm \mathbf{2 . 5 1}$ & $\mathbf{- 4 . 5 5} \pm \mathbf{1 . 8 8}$ & $\mathbf{0 . 0 2 2}$ \\
\hline Li-EL & $\mathbf{0 . 3 0} \pm \mathbf{1 . 2 7}$ & $\mathbf{- 0 . 8 2} \pm \mathbf{1 . 4 8}$ & $\mathbf{0 . 0 2 1 ^ { * }}$ \\
\hline Ls curvature & $2.76 \pm 1.05$ & $2.14 \pm 1.16$ & 0.266 \\
\hline Li curvature & $0.88 \pm 1.49$ & $0.58 \pm 1.38$ & 0.442 \\
\hline A-SN & $14.04 \pm 2.79$ & $13.79 \pm 0.80$ & 0.777 \\
\hline Ls strain & $12.87 \pm 2.51$ & $13.03 \pm 3.51$ & 0.90 \\
\hline Ls strain factor & $1.45 \pm 1.65$ & $1.53 \pm 172$ & 0.815 \\
\hline B-SLi & $10.31 \pm 1.80$ & $10.19 \pm 1.27$ & 0.875 \\
\hline Li strain & $12.03 \pm 2.25$ & $12.51 \pm 3.0$ & 0.609 \\
\hline Li strain factor & $-1.32 \pm 1.20$ & $-1.71 \pm 1.97$ & 0.450 \\
\hline Ns-PGs / FH & $\mathbf{8 . 4 3} \pm \mathbf{3 . 7 7}$ & $\mathbf{5 . 3 4} \pm \mathbf{5 . 0 5}$ & $\mathbf{0 . 0 3 3}$ \\
\hline U:L ST facial height & $106.34 \pm 14.73$ & $99.56 \pm 10.06$ & 0.101 \\
\hline Chin thickness & $11.12 \pm 1.32$ & $10.67 \pm 1.56$ & 0.596 \\
\hline
\end{tabular}

*: Statistically significant at $\mathrm{P} \leq 0.05$ 
Egyptian

Orthodontic Journal
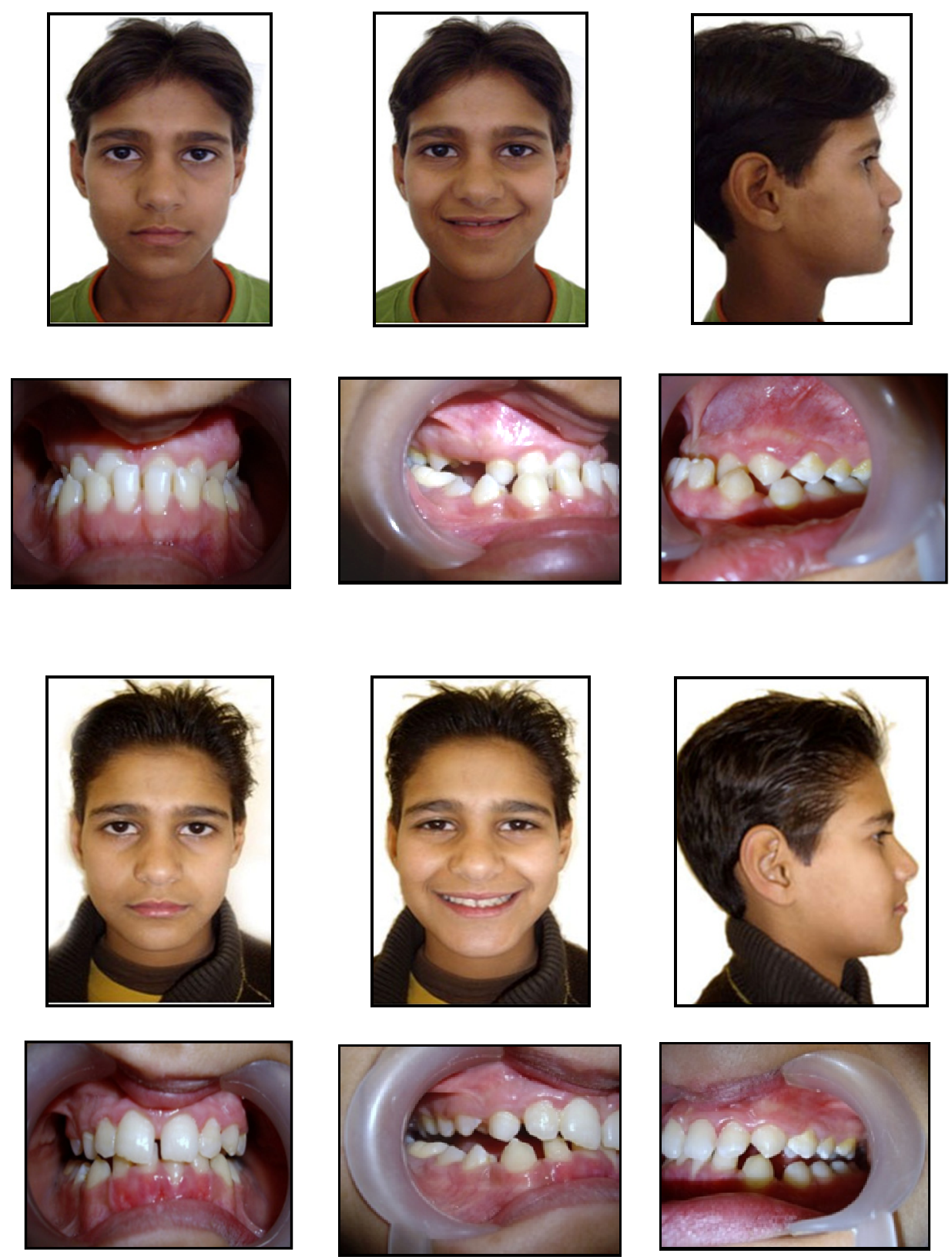

Volume 43 - June 2013 

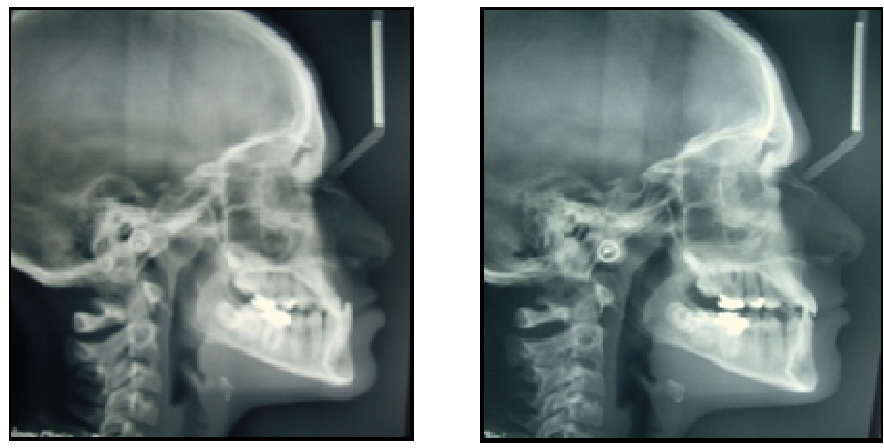

Fig. 9: Comparison between pre and post treatment photos and lateral cephalometric xrays of patient 1 .

\section{DISCUSSION}

The Class III splints was the appliance chosen to be tested in this study as it is an intraoral appliance, so when compared to other extraoral appliances, it has a reduced psychological impact on the patient during treatment. The patients were chosen in the age range of 8-10 years for female patients and from 8-12 years for male patients to ensure remaining growth potential. ${ }^{25}$ The patients that were subjected to orthodontic or orthopaedic treatment were excluded as not to have any effect on the accuracy of the results. The design of the Class III splints in this study was similar to those previously tested by other studies ${ }^{22-24,27}$ so that the results could be easily compared. Clear acrylic splints were used in the previous studies. $^{23,24}$ In this study colored acrylic splints were used as it was found to attract the patient's more ${ }^{28}$ and thereby they were more motivated to wear the appliance. Digital tracing by computer software was the choice for measurements calculation, as it easily enables the calculation of a large number of measurements. It was important that the software to be chosen was one that was reported to be accurate and valid. The software chosen was FACAD ${ }^{\circledR}$. FACAD ${ }^{\circledR}$ (Ilexis AB, Linköping, Sweden) which is a program used for cephalometric analysis. It was reported that Digital tracing with FACAD ${ }^{\circledR}$ is sufficient for clinical purposes and comparable with manual cephalometric tracings. ${ }^{29}$ At the 
Egyptian

Orthodontic Journal

time of crossbite correction, the appliance resulted in a posterior openbite that was observed clinically in most of the patients. This openbite was closed after about three to four months by upper and lower teeth overeruption, which was observed in the post treatment follow up visits of the patients.

Skeletal results analysis: The angular skeletal statistical analysis showed a significant increase in the ANB angle. This coincided with Franchi and Baccetti ${ }^{22}$ and El-Harouni ${ }^{24}$ results, but not with El Kenany and Ismail ${ }^{23}$ results. This may be due to the smaller sample size tested in the study ${ }^{23}$ as well as the different force magnitude used. There was no significant change in the SNA angle which coincides with El Kenany and Ismail $^{23}$ and Franchi and Baccetti ${ }^{22}$ but not with El-Harouni ${ }^{24}$. This may be due to the higher elastic force used and longer duration of wear in El-Harouni study ${ }^{24}$. Also the advancement may have occurred due to growth. There was also no significant decrease in the SNB angle which coincides with El Kenany and Ismail ${ }^{23}$ but not with Franchi and Bacetti ${ }^{22}$ and El-Harouni ${ }^{24}$, may be due to the longer duration of wear and greater force level used in their studies. ${ }^{22,24}$ The significant change in the ANB angle regardless the nonsignificant change in the SNA and SNB angles indicates that the skeletal change is due a combination of both maxillary advancement and mandibular retrusion together, but there is no significant change on any of them individually. Therefore, the Class III splint can be more effective in the treatment of Class III patients due to a combination of both maxillary retrusion and mandibular protrusion. There was a significant increase in the mandibular plane to Frankfort plane angle indicating a clockwise rotation of the mandible, an increase in the mandibular steepness leading to a shallower anterior overbite and an opened posterior bite that was clinically observed. This result coincides with Franchi and Baccetti ${ }^{22}$ and El-Harouni ${ }^{24}$ results, but not with El Kenany and Ismail ${ }^{23}$. This may be due to the smaller sample size and different force level used in El Kenany and Ismail study. ${ }^{23}$ There was also a significant increase in the convexity angle, but this measurement wasn't measured in any of the previous studies. ${ }^{22-24}$ However, there was a significant decrease in the occlusal plane to Frankfort horizontal plane angle, indicating anterior upward tipping of the occlusal plane. This was 
Egyptian

Orthodontic Journal

only measured in El Kenany and Ismail study ${ }^{23}$ but it showed in their study no significant difference. This may be due to the smaller sample size, lighter force used or changes in the angulation of the occlusal plane before and after treatment due to the eruption of the first molars in patients that started treatment in the late deciduous stage and ended in the early mixed dentition stage. The palatal plane angulation (FH/NL-angle) didn't show significant change. This result coincides with El-Kenany and Ismail ${ }^{23}$ study, but not with Franchi and Baccetti ${ }^{22}$, may be due to their smaller sample size. Palatal plane angulation was not measured by El-Harouni ${ }^{24}$ study. The SNPog showed a nonsignificant change. This result coincided with El-Harouni ${ }^{24}$ results, while it wasn't measured in the other two studies. $^{22,23}$ The linear skeletal results showed a significant increase in the Wits appraisal, although there is a probable effect of the occlusal plane tipping on this change. This change coincided with El-Harouni ${ }^{24}$ results, but not with El Kenany and Ismail ${ }^{23}$, while it wasn't measured in Franchi and Baccetti's study. ${ }^{22}$ This may be due the fact that there was no significant change in the ANB angle in El Kenany and Ismail study ${ }^{23}$, indicating no change in either the A or B points and there was also no significant change in the occlusal plane to Frankfort Horizontal Plane angle. Although there was a significant downward rotation of the mandible, it wasn't accompanied by a significant increase in the lower anterior facial height. This result coincided with El-Harouni ${ }^{24}$ and El Kenany and Ismail ${ }^{23}$ results, but not with Franchi and Baccetti's ${ }^{22}$ results. This may be due to the smaller sample size tested in their study ${ }^{22}$ as compared to this study and the other studies. ${ }^{23,24}$ As regards the posterior facial height, it didn't change significantly in this study or in El-Harouni ${ }^{24}$ and El Kenany and Ismail ${ }^{23}$ studies. There was no significant change in the maxillary and mandibular length, which coincided with Franchi and Baccetti $^{22}$, while they were not measured by El-Harouni ${ }^{24}$ and El Kenany and Ismail. ${ }^{23}$

Dental results analysis: There was a significant increase in the IsL/FH angle indicating proclination of the upper incisors. This result coincided with all three studies. ${ }^{22-24}$ There was also a significant increase in the linear measurement Is-NP indicating a forward movement of the upper incisor crown which coincides with the upper incisor proclination

Volume 43 - June 2013 
Egyptian

Orthodontic Journal

result. There was a significant decrease in the IiL/ML indicating retroclination of the lower incisors. This result coincided with all studies. $^{22-24}$ There was also a significant decrease in the linear measurement Ii-NP indicating backward movement of the lower incisor crown which coincides with the lower incisor retroclination. Clinically the anterior cross bite with which all the cases started changed into a positive overjet ranging from one to three millimeters. This was evidenced statistically by a significant increase in the overjet. This result coincided with El-Harouni ${ }^{24}$ results and it wasn't tested in the other studies. ${ }^{22,23}$ However, there was a significant decrease in the overbite; this was due to the clockwise rotation of the mandible and the increase in the mandibular steepness. So, the patients that started with a deep bite ended up with a normal overbite of about $2-3 \mathrm{~mm}$, and the patients that started with a normal overbite ended up with a shallow bite. That's why the Class III splints is a good choice for Class III patients with a deepbite as was reported by Franchi and Bacetti ${ }^{22}$ and El Kenany and Ismail ${ }^{23}$ (unless it will be accompanied with phase II extraction or with the use of high pull head gear). On the contrary, El-Harouni study ${ }^{24}$ showed no significant change in the overbite measurement, although it also showed an increase in the mandibular steepness as this study. There was a significant increase in the $\mathrm{MsL} / \mathrm{FH}$ angle indicating upper molar proclination and a significant decrease in the MiL/ML angle indicating retroclination of the lower molar. There was also a significant change in the molar relation which was evidenced by a significant increase in the molar relation measurement. This was due to forward tilting of the upper molar and backward tilting of the lower molar. This showed clinically, where the Class III molar relation was changed to a Class I molar relation and in some cases reached to be a Class II molar relation. This overcorrection of the molar relation was also observed clinically in Franchi and Bacetti study. ${ }^{22}$ The linear measurements Ms-m-NP and Mi-m-NP however showed no significant change indicating no significant movement of the upper and lower molars crowns, although the molar relation showed a significant change. This means that the movement of each molar alone wasn't significant but their combined movement together and relevant to each other was. All molars measurements were not tested statistically in all the past studies. ${ }^{22-24}$

Volume 43 - June 2013 
Soft tissue results analysis: The soft tissue profile of the patients showed a marked clinical improvement that was obvious to the parents and the patients themselves; similar to what was reported by El Harouni. ${ }^{24}$ The profile was improved by a change in the position of the soft tissue chin, and upper and lower lips which was obvious clinically and also showed statistical significance. Soft tissue effects were tested only by El Harouni ${ }^{24}$ and not by the other studies. ${ }^{22,23}$ There was a backward movement of the soft tissue chin (represented by the 'PGs' landmark) and this was evidenced by a significant decrease in the Facial ST angle, along with a significant decrease in the Ns-PGs/FH measurement. There was also a significant change in the lips position evidenced by a significant decrease in the Ls-EL measurement, indicating forward movement of the upper lip, and a significant increase in the Li-EL measurement indicating backward movement of the lower lip. These soft tissue measurements were not tested by El-Harouni ${ }^{24}$, however the study measured the upper and lower lip thickness as a distance from the most anterior part on the convexity of the lip to the line SN-PGs. The SN-PGs line is defined by landmarks that are subjected to changes by the appliance. The study ${ }^{24}$ showed a significant decrease in the lower lip thickness, but not in the upper lip thickness. In this study however, the upper and lower lip thickness were measured in another way, by the measurements "Ls strain" for the upper lip and "Li strain" for the lower lip. These measurements were taken on a fixed plane that is not subjected to changes by the appliance (Frankfort horizontal plane).These measurements showed no significant change, which doesn't coincide with El Harouni ${ }^{24}$ significant change in the lower lip thickness measurement. So, the change detected by El Harouni ${ }^{24}$ may be due to a change in the PGs (soft tissue Pogonion) landmark position that lead to the decrease in the lower lip thickness measurement, and not due to a true change in the thickness. In addition to all the previously mentioned soft tissue measurements, the nasolabial angle, nasiolabial and mentolabial sulci depth (represented by the Ls and Li curvature), U: L soft tissue facial height and chin thickness were evaluated in this study, but were not evaluated in the previous studies. $^{22-24}$ All these measurements showed no significant change indicating that the appliance had no effect on them. 
Egyptian

Orthodontic Journal

\section{CONCLUSION}

Class III splints can be used in the treatment of growing skeletal Class III malocclusion that is due to a combination of maxillary retrusion and mandibular protrusion. It is more indicated though with deep bite cases, unless it will be followed with phase II extraction or with the use of high pull head gear.

\section{REFERENCES}

1. Arman A, Toygar TU, Abuhijleh E. Profile changes associated with different orthopedic treatment approaches in Class III malocclusions. Angle Orthod 2004;74:733-40.

2. Staudt CB, Kiliaridis S. Different skeletal types underlying Class III malocclusion in a random population. Am J Orthod Dentofacial Orthop 2009;136:715-21.

3. Ferro A, Nucci NP, Ferro F, Gallo C. Long-term stability of skeletal Class III patients treated with splints, Class III elastics, and chincup. Am J Orthod Dentofacial Orthop 2003;123:423-34.

4. Ngan P, Hägg U, Yiu C, Merwin D, Wei SH. Treatment response to maxillay expansion and protraction. Eur J Orthod 1996;18:151-68.

5. Cozzani G. Extraoral traction and Class III treatment. Am J Orthod 1981;80:638-50.

6. Yüksel S, Uçem TT, Keykubat A. Early and late facemask therapy. Eur J Orthod 2001;23:559-68.

7. Halim H, Budihardja A. Dentoskeletal effects and facial profile changes in Class III patient treated with protraction facemask appliance: a case report. World J Orthod 2012;1:73-7

8. Chun YS, Jeong SG, Row J, Jang SJ. A new appliance for orthopedic correction of Class III malocclusion. J Clin Orthod 1999;32:705-11.

9. Klempner LS. Early Orthopedic Class III treatment with a modified tandem appliance. J Clin Orthod 2003;37:218-23.

10. Abdelnaby YL, Hafez AM, Dae'r AA. Evaluation of modified tandem appliance in management of cases with maxillary retrusion. Egypt Orthod J 2009;36:101-17. 
Egyptian

Orthodontic Journal

11. Graber LW. Chincup therapy for mandibular prognathism. Am J Orthod Dentofacial Orthop 1977;72:23-41.

12. Deguchi T, Kuroda T, Minoshima Y, Graber TM. Craniofacial features of patients with Class III abnormalities: growth -related changes and effects of short-term and long-term chin cup therapy. Am J Orthod Dentofacial Orthop 2002;121:84-92.

13. Fränkel R. Maxillary retrusion in Class 3 and treatment with the function corrector 3. Rep Congr Eur Orthod Soc 1970; 46:249-59.

14. Kinder G, DiBiase A, DiBiase D. Class III twin blocks: a case series. J Orthod 2003;30:197-201.

15. Tuncer C, Uner O. Effects of a magnetic appliance in functional Class III patients. Angle Orthod 2005;75:768-77.

16. Tollaro I, Bacetti T, Franchi L. Mandibular skeletal changes induced by early functional treatment of Class III malocclusion: a superimposition study. Am J Orthod Dentofacial Orthop 1995; 108:525-32.

17. Ucem TT, Ucuncü N, Yüksel S. Comparison of double-plate appliance and facemask therapy in treating Class III malocclusions. Am J Orthod Dentofacial Orthop 2004;126:672-9.

18. Heymann GC, Cevidanes L, Cornelis M, De Clerck HJ, Tulloch JFC. Three-dimensional analysis of maxillary protraction with intermaxillary elastics to miniplates. Am J Orthod Dentofacial Orthop 2010;137:274-84

19. Cevidanes L, Baccetti T, Franchi L, McNamara JA Jr, De Clerck H. Comparison of two protocols for maxillary protraction: bone anchors versus face mask with rapid maxillary expansion. Angle Orthod 2010;80:799-806.

20. Cha BK, Choi DS, Ngan P, Jost-Brinkmann PG, Kim SM, Jang IS. Maxillary protraction with miniplates providing skeletal anchorage in a growing Class III patient. Am J Orthod Dentofacial Orthop 2011;139:99-112. 
21. Baccetti T, De Clerck HJ, Cevidanes LH, Franchi L. Morphometric analysis of treatment effects of bone-anchored maxillary protraction in growing Class III patients. Eur J Orthod 2011;33:121-5.

22. Franchi L, Baccetti T. Splint therapy skeletal Class III malocclusion in the primary dentition. J Clin Pediat Dent 1998;22:93-8.

23. El Kenany W, Ismail H. Early treatment of Class III malocclusion using intraoral splints or face mask. A comparative study. Egypt Orthod J 2001;20:1-13.

24. El Harouni NM. Skeletal, dental and soft tissue changes following the treatment of Class III malocclusion using the Class III splint. Egypt Orthod J 2008;34:1-14.

25. Proffit WR, Fields HW Jr, Sarver DM. Contemporary Orthodontics. 4th ed. Mosby; 2007:497.

26. Proffit WR, Fields HW Jr, Sarver DM. Contemporary Orthodontics. 4th ed. Mosby; 2007:353.

27. Adams CD, Meikle MC, Norwick KW, Turpin DL. Dentofacial remodelling produced by intermaxillary forces in Macaca mulatta Arch. Arch Oral Biol 1972;17:1519-35.

28. Kupietzky A. Clinical technique: removable appliance therapy for space maintenance following early loss of primary molars. Eur Arch Paediatr Dent 2007;8:30-4.

29. Naoumova J, Lindman R. A comparison of manual traced images and corresponding scanned radiographs digitally traced. Eur J Orthod 2009; 31:247-53. 